\title{
MECHANICAL BEHAVIOR AND TEXTURE EVOLUTIONSTUDYOF MEDIUM CARBON STEEL WIRES DURING INDUSTRIAL WIRE-DRAWING PROCESS
}

\author{
Mosbah ZIDANI ${ }^{1}$, Mohamed Chaouki NEBBAR ${ }^{1,2}{ }^{2}$, Toufik DJIMAOUI ${ }^{1}$, Salim MESSAOUDI ${ }^{1}$, \\ Hichem FARH ${ }^{3,4}$, Anne Laure HELBERT ${ }^{5}$, François BRISSET ${ }^{5}$, Thierry BAUDIN ${ }^{5}$ \\ 1 Université Mohamed Khider Biskra, Laboratoire de Génie Energétique et Matériaux (LGEM) Faculté des \\ Sciences et de la Technologie, Biskra, Algeria \\ ${ }^{2}$ Centre de Recherche Scientifique et Technique en Analyses Physico-chimiques (CRAPC) BP 384, Bou- \\ Ismail, Tipaza, Algeria \\ ${ }^{3}$ Department of Material Sciences, Faculty of Exact Sciences, University of Tebessa, Algeria \\ ${ }^{4}$ Laboratoire des Composants Actif et Matériaux, Université d' Oum el Bouaghi, Algeria \\ ${ }_{5}^{5}$ ICMMO, SP2M, Univ. Paris-Sud, Université Paris-Saclay, Orsay, France, EU
}

https://doi.org/10.37904/metal.2019.683

\begin{abstract}
The medium carbon steel drawn wires are used in wide variety of applications, such as bridge cables, tire cord and springs. Wire drawing is a cold working process. It issued for reducing the cross-section (the diameter) of a wire by plastic deformation, in the presence of a dry lubricant powder, called soap. An electron backscatter diffraction (EBSD) was developed which allow non-destructive evaluation of crystallographic orientation distribution in materials has been used in this study.

This present research paper focuses on the characterization of the texture, microstructural evolution and mechanical properties behaviour (hardness and torsion) of medium carbon steel wires obtained by wire drawing process at Tréfissoud (Company used for the manufacturing of the spring mattress). The study was carried out respectively on the two states of the wires, wire rod and drawn wire ( $47 \%$ and $56 \%$ of deformation level), using the scanning electron microscopy (SEM) for examination of the microstructure, the electron backscatter diffraction (EBSD) for crystallographic orientation distribution analysis, the hardness and torsion to follow the curing of the studied wires.
\end{abstract}

Keywords: Medium carbon steel, drawn wire, spring mattress, texture, microstructure, hardness, torsion

\section{INTRODUCTION}

Wire drawing process has an important role in the industrial production of carbon steel products. It is a manufacturing method used for reducing the diameter of wires by pulling the wire through a die. The wire is pulled through a conical aperture called a die to reduce its diameter [1,2]. During this process, the microstructure of steel material changes which affect its mechanical properties [3,4]. Generally, wire rod is made from carbon steel. The carbon steel wires are used as a product at cables, electrodes and springs [5].

\section{EXPERIMENTAL PROCEDURE}

Medium carbon steel wires used in this study produced by Tréfisoud Company, JSC from Algeria. The chemical composition of the wires was shown in Table1.

Firstly, mechanical surface cleaning has been done to remove oxide layer on wires. Following this process orderly chemical pickling, washing, lime bath and drying processes were applied and then the drawing process is carried out at room temperature. 
Table 1 Chemical composition of medium carbon steel (wt\%)

\begin{tabular}{|c|c|c|c|c|c|c|c|}
\hline $\mathbf{C}$ & $\mathbf{M n}$ & $\mathbf{S i}$ & $\mathbf{P}$ & $\mathbf{S}$ & $\mathbf{C r}$ & $\mathbf{N i}$ & $\mathbf{C u}$ \\
\hline 0.675 & 0.649 & 0.18 & 0.008 & 0.017 & 0.051 & 0.036 & 0.048 \\
\hline
\end{tabular}

Two types of wire are studied (wire rod $(0 \%)$ and deformed wires with two different reduction $(47 \%$ and $56 \%)$. The deformation level is calculated from the equation [6]:

$\varepsilon=\frac{(S-s)}{S} \cdot 100 \quad(\%)$

Where:

$S$ is the section of wire rod and $s$ is the section of deformed wire.

To observe the microstructure by SEM, the samples were subjected to mechanical polishing performed on SiC abrasive papers of different grain sizes with oil-based diamond. After the mechanical polishing, the samples were chemically etched with Nital $3 \%$ to reveal microstructure.

Microstructural and textural analyzes were done using scanning electron microscopy FEl quanta 250 and TSL EDAX electron backscatter diffraction in the scanning electron microscopy Zeiss 940 equipped with OIMTM. The Vickers hardness measurement was carried out by applying $500 \mathrm{~g}$ load, according to NF EN ISO 65071:2005 standard. The number of twist was determined by torsion tests according to ISO 18338:2015 standard.

\section{RESULTS AND DISCUSSION}

\subsection{Microstructure}

Figure1 presents the microstructure wire after successive cold drawing, all in longitudinal section.
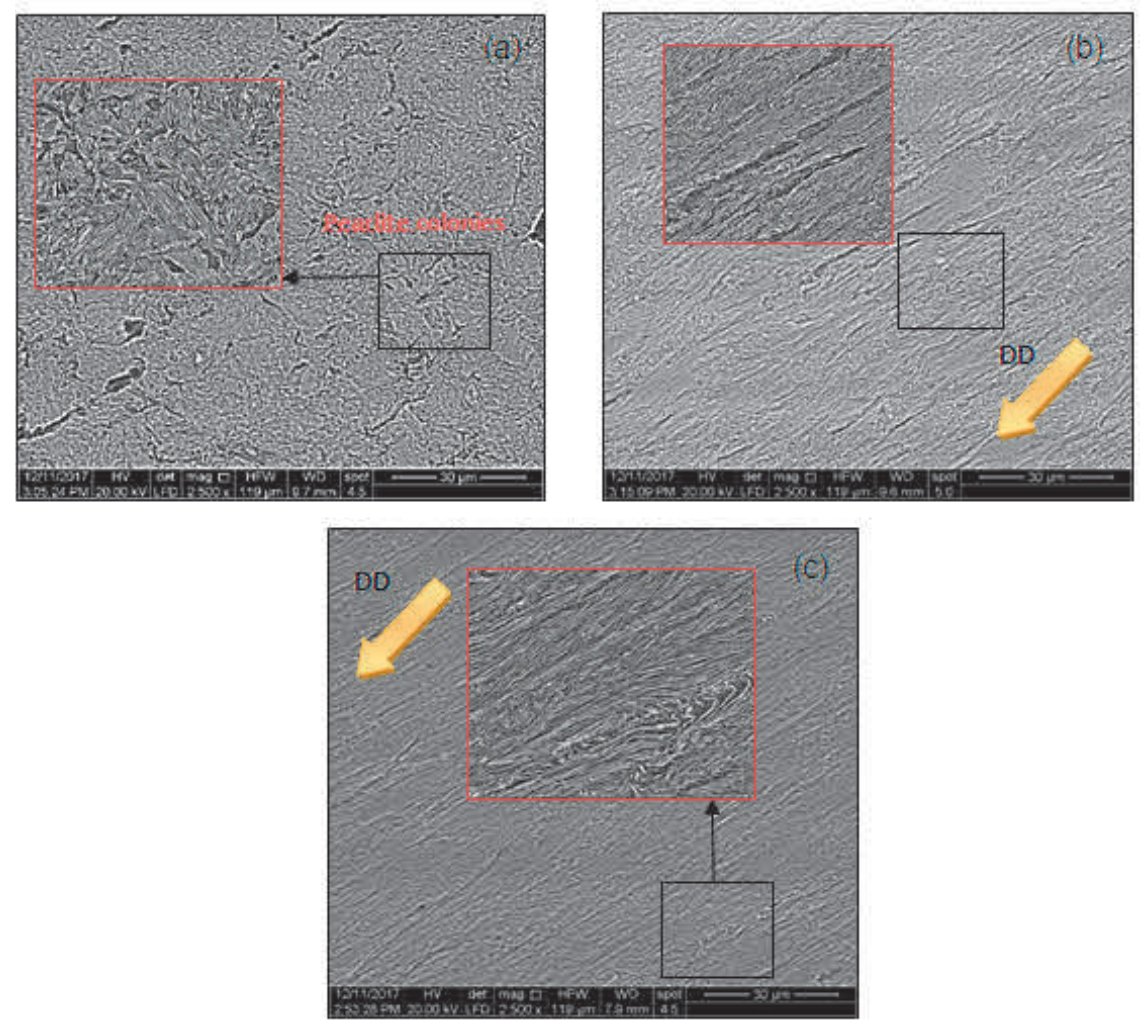

Figure 1 Scanning electron micrographs for the wire samples drawn to different levels: (a) $0 \%$, (b) $47 \%$ and (c) $56 \%$. 
The microstructure of steel wire rod (Figure 1-a) shows a random distribution (isotropy) of the pearlite colonies. After drawing (Figure 1-b and Figure 1-c), microstructures are significantly different and very fine grains are oriented in the drawing direction, the cementite lamellae are elongated in the drawing direction (DD). This elongation is the result of the development of fiber texture $<110>$ in the drawing direction (DD) $[7,8]$.

\subsection{Texture}

Deformation textures are also shown in the ODFs plots $\left(\varphi 2=45^{\circ}\right)$ for the wire rod and drawn wires in Figure 2, respectively.
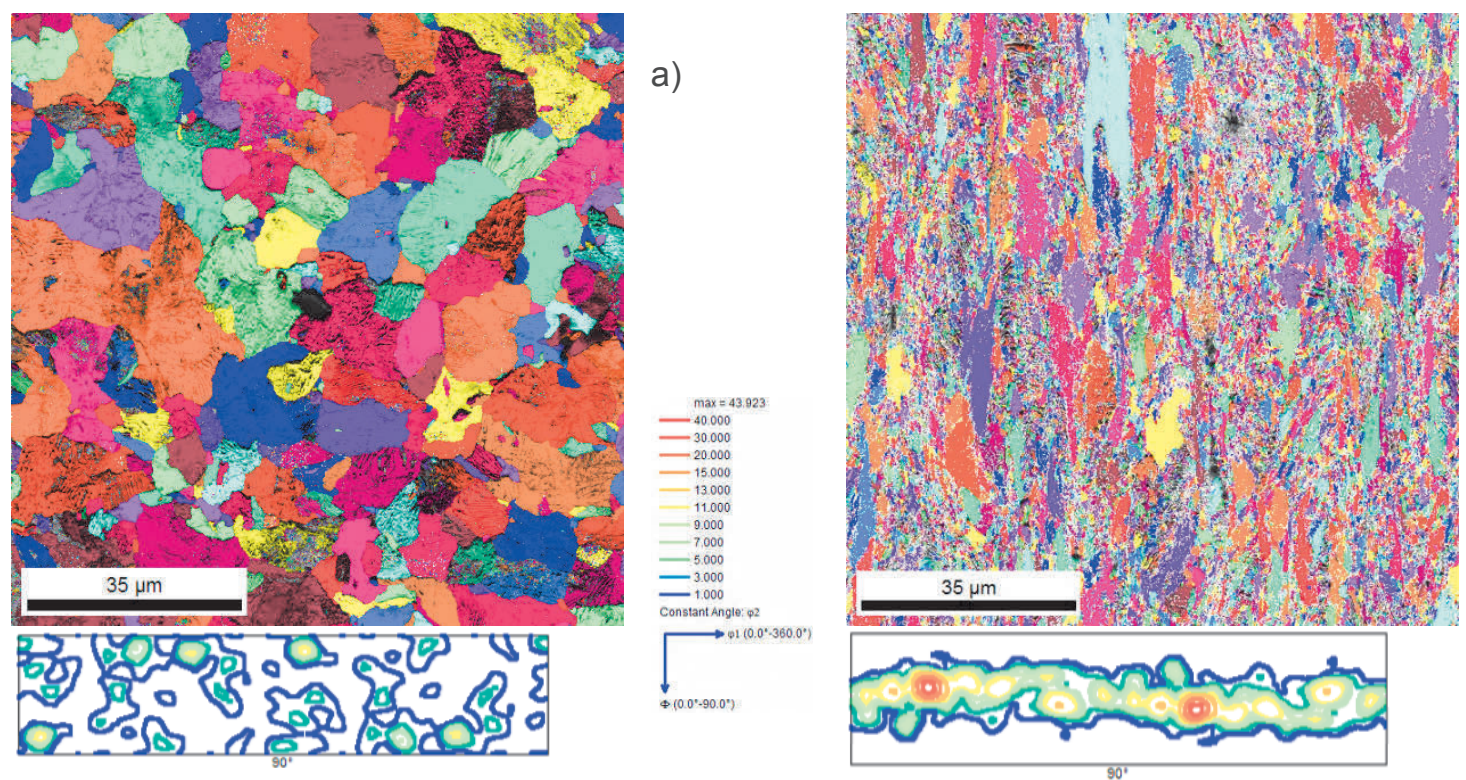

b)

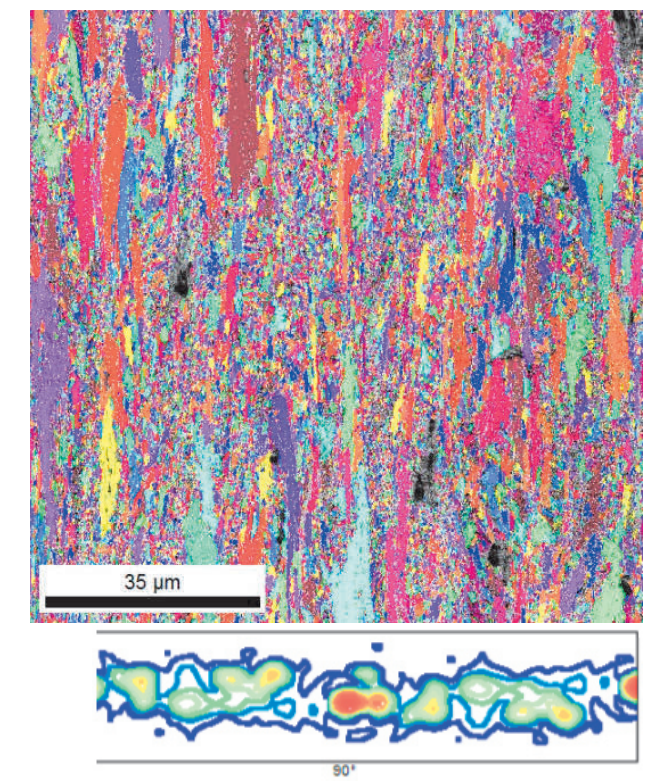

c)
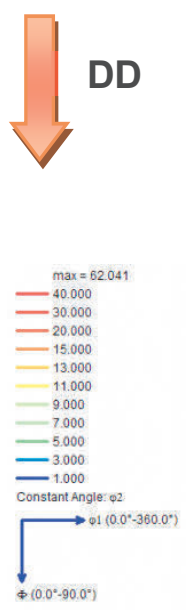

Figure 2 Electron backscatter diffraction microstructure and orientation distribution function calculated by EBSD of the medium carbon steel wire samples drawn to different levels:

(a) $0 \%$ (b) drawn wire at $47 \%$ and (c) $56 \%$.

The quantitative analysis show the development of the fiber $<110>/ / D D$ (DD = drawing direction) with the maximum ODF density with 34.923 and 62.041 for the $47 \%$ and $56 \%$ drawn sample, respectively. The principal component $(\{111\}<110>)$ of the fiber increases with the increasing of the deformation level [9]. 


\subsection{Hardness}

Figure 3 shows the effect of wire drawing level on the hardness. After the drawing process, the generation of high dislocation density in the crystal structure of medium carbon steel and the refining of inter-lamellar spacing leads to the increase in hardness $[10,11]$.

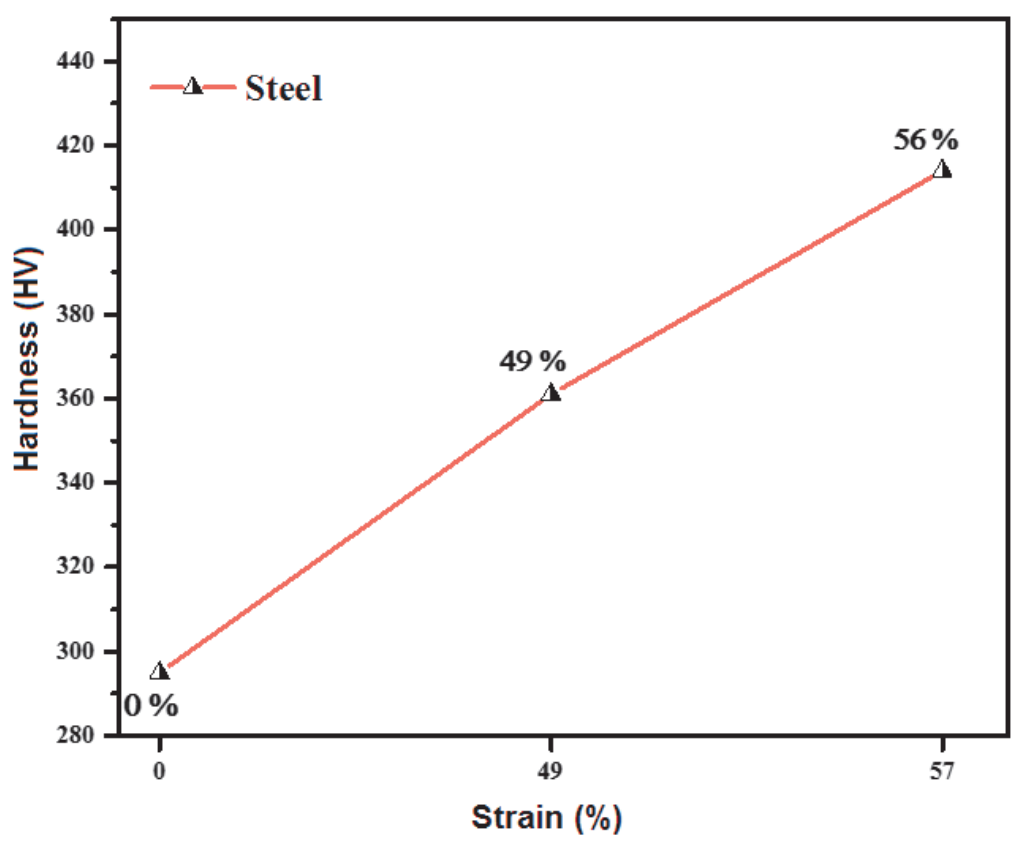

Figure 3 Hardness evolutions of medium carbon steel wires

\subsection{Torsion testing}

The torsion properties of the medium carbon steel wires are shown in Figure 4. It is observed that number of twist to failure during torsion testing of medium carbon steel increase with increasing of drawing level.

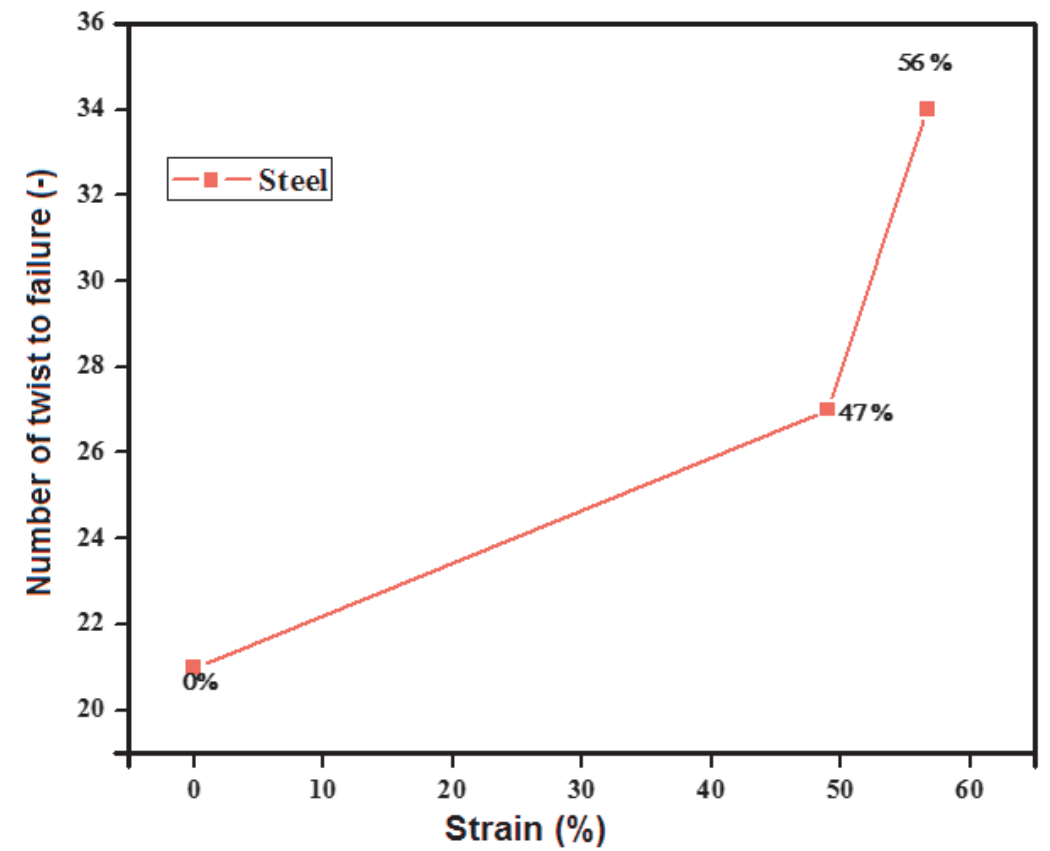

Figure4 Influence of number of twists to failure on deformation level of medium carbon steel wires 


\section{CONCLUSION}

The wire drawing process of medium carbon steel wires has been studied. This study aims to the know of some processes that affect microstructure, texture, hardness and torsion properties of drawn wires which appeared during the drawing process. The following conclusion can be done from this study:

- $\quad$ The drawing produces microstructural orientation in medium carbon steel, so that cementite lamellae orientate in the drawing direction (DD), while its inter-lamellar spacing decreases during process.

- $\quad$ The drawing causes the development of majority fiber texture $<110>/ / D D$ (DD = drawing direction). The principal component $(\{111\}<110>)$ of the fiber increases with the increasing of the deformation level.

- The hardness test shows that wire drawing increases hardness by generating new dislocations in the crystalline structure and by decreasing of inter-lamellar spacing.

- $\quad$ The experiments have shown that the torsion twist increase when reduction level is increased.

\section{ACKNOWLEDGEMENTS}

\section{This work is done in collaboration with the company Tréfissoud}

\section{REFERENCES}

[1] TIERNAN, P. and HILLERY, M.T., Analysis of wire manufacture using the die less drawing method, Journal of Manufacturing Processes, 2008. vol. 10, no. 1, pp. 12-20.

[2] CETINARSLAN, C.S., A study on influence of some process parameters on cold drawing of ferrous wires. Indian Journal of Engineering \& Materials sciences, 2012. Vol.19, pp.221-228,

[3] HASAN, M.F., Analysis of mechanical behavior and microstructural characteristics change of ASTM A-36 steel applying various heat treatment. Journal of Material Sciences and Engineering, 2016. vol. 5, pp.227-232,

[4] RAJI, N.A. and OLUWOLE, O.O., Influence of degree of cold-drawing on the mechanical properties of low carbon steel. Materials Sciences and Applications, 2011. vol.2, pp.1556-1563.

[5] ÇETINARSLAN, C.S. and GÜZEY, A., Tensile properties of cold-drawn low-carbon steel wires under different process parameters, Materials and Technology, 2013. vol.47, pp. 245-252.

[6] RAJI, N.A. and OLUWOLE, O.O., Mechanical properties of cold-drawn low carbon steel for nail manufacture: experimental observation, Research Journal of Applied Sciences, Engineering and Technology, 2013. vol.5, pp.118-122.

[7] KUMAR, P., GURAO, N.P., HALDAR, A. and SUWA, S., Progressive changes in the microstructure and texture in pearlitic steel during wire drawing, ISIJ international, 2011. vol.51, pp.679-684.

[8] ZIDANI, M., MESSAOUDI, S., BAUDIN, T., SOLAS, D. and MATHON, M. H., Deformation textures in wire drawn pearlitic steel, International Journal of Material Forming, 2010. vol.3, pp.7-11.

[9] ZIDANI, M., MESSAOUDI, S., BAUDIN, T., SOLAS, D., DERFOUF, C. and BOUNAR, N., Evolution of deformation and recrystallization textures of a steel drawn wire", In METAL 2008: 17th International Conference on Metallurgy and Materials. Ostrava: TANGER, 2008,

[10] HOSSAIN, R., PAHLEVANI, F. and SAHAJWALLA, V., Evolution of microstructure and hardness of high carbon steel under different compressive strain rates", Metals, 2018. vol.8, pp.1-10.

[11] MODIA, O.P., DESHMUKHB, N., MONDALA, D.P., JHAA, A.K., YEGNESWARANA, A.H. and KHAIRA, H.K., Effect of interlamellar spacing on the mechanical properties of $0.65 \%$ C steel, Materials Characterization, 2001. vol.4, pp.347-352. 